\title{
Valorização de produtos alimentares tradicionais: os usos das indicações geográficas no contexto brasileiro
}

Jaqueline Sgarbi Santos*

Renata Menasche**

Recibido: 2014-03-19 Aprobado: 2014-08-28 Disponible en línea: 2015-15-03

doi:I0.III44/Javeriana.cdrı2-75.vpat

Cómo citar este artículo: Sgarbi S. J., \& Menasche, R. (2015). Valorização de produtos alimentares tradicionais: os usos das indicações geográficas no contexto brasileiros. Cuadernos de Desarrollo Rural, I2(75), II-3I. http://dx.doi. org/10.III44/Javeriana.cdrı2-75.vpat

\footnotetext{
* Engenheira Agrônoma/UFPel-Mestre em Agroecossistemas-UFSC-Doutoranda em Sistemas de Produção Agrícola Familiar-SPAF/UFPel. Universidade Federal de Pelotas (Brasil). Email: sgarbijaqueline@yahoo.com.br

** Doutora em Antropologia Socia, Programa de Pós-Graduação em Antropologia da Universidade Federal de Pelotas (PPGAnt/UFPel) e Programa de Pós-Graduação em Desenvolvimento Rural da Universidade Federal do Rio Grande do Sul (PGDR/UFRGS). Email: renata.menasche@pq.cnpq.br
} 


\section{Resumo}

Os produtos alimentares tradicionais fazem parte de um sistema em que utensílios e saberes estão imbricados aos modos de vida das famílias produtoras. Em um contexto em que observamos crescente desconfiança da origem dos alimentos, os produtos alimentares tradicionais tornam-se fundamentais para identificação da origem e manutenção da cultura. Atualmente, as Indicações Geográficas (IGs) surgem para valorização desses sistemas. Contudo, ainda que a constituição de IGs se apresente como perspectiva interessante não pode ser tomadas como fim em si. É importante que cada sistema seja apreendido em sua singularidade, para então, identificar-se a melhor estratégia para sua preservação.

\section{Palavras-chave:}

conhecimento tradicional; cultura alimentar; campesinato; propriedade intelectual

\section{Valorización de los productos alimenticios tradicionales: usos de las indicaciones geográficas en el contexto brasileño}

\section{Resumen}

Los productos alimenticios tradicionales hacen parte de un sistema en que los utensilios y los saberes están imbricados a los modos de vida de las familias productoras. En un contexto en que se observa una creciente desconfianza sobre el origen de los alimentos, los productos alimenticios tradicionales se vuelven fundamentales para identificar el origen y mantener la cultura. Actualmente, las Indicaciones Geográficas (IG) surgen para la valorización de estos sistemas. Sin embargo, a pesar de que la constitución de IG se presente como una perspectiva interesante no puede ser tomada como un fin en sí mismo. Es importante que cada sistema sea comprendido en su singularidad, para entonces, identificar la mejor estrategia para su preservación.

\section{Palabras clave:}

conocimiento tradicional; cultura alimentaria; campesinado; propiedad intelectual 


\title{
Valuation of Traditional Food Products: Use of Geographical Indications in the Brazilian Context
}

\begin{abstract}
Traditional food products are part of a system in which tools and knowledge are interwoven with the way of life of producer families. We observe in this context a growing mistrust regarding the origin of food, so in it, traditional food products become key to identify the origin and preserve the culture. Currently, Geographical Indications (IGs) arise for the valuation of these systems. However, although constituting IGs may seem as an interesting perspective, it cannot be assumed as an end by itself. It is important that the individual characteristics of each system are understood in order to identify the best strategy for its preservation.
\end{abstract}

Keywords:

traditional knowledge; food culture; peasantry; intellectual property

\section{Mise en valeur des produits alimentaires traditionnels : usages des indications géographiques dans le contexte brésilien}

\section{Résumé}

Les produits alimentaires traditionnels font partie d'un système où les outils et les savoirs se lient aux styles de vie des familles productrices. Dans un contexte où l'on observe de plus en plus une méfiance par rapport à l'origine des aliments, les produits alimentaires traditionnels commencent à être fondamentaux pour identifier l'origine et garder la culture. Maintenant, les indications Géographiques (IG) apparaissent pour développer ces systèmes. Cependant, même si la constitution d'IG soit présentée en tant qu’une perspective intéressante elle ne peut pas être prise en tant qu'une fin en soi. Il est important que chaque système soit compris dans sa singularité, et ainsi on identifie la meilleure stratégie pour sa préservation.

Mots-clés:

connaissance traditionnelle; culture alimentaire; paysans; propriété intellectuel 


\section{Introdução}

O presente artigo se insere na discussão sobre produtos alimentares tradicionais característicos de um território ${ }^{\mathrm{I}}$ e os desafios para sua preservação. Pretende discutir os possíveis caminhos para a valorização desses produtos num cenário em que se confrontam a preservação de práticas e saberes a eles associados e os instrumentos legais de salvaguarda. No caso específico de produtos alimentares, faz-se ainda necessária atenção à legislação que rege a produção, circulação e comercialização de alimentos no Brasil. Nos campos acadêmico e das políticas públicas, intensificam-se discussões acerca de produtos tradicionais, de territórios específicos, e sua importância como parte de sistemas que conformam modos de ser, de viver e de criar de cada região, constituindo identidades e expressões dos grupos sociais.

No presente artigo, discutiremos a crescente utilização das Indicações Geográficas (IGs) como ferramenta de proteção de produtos tradicionais alimentares. Ademais de elucidar vantagens e possibilidades, tão amplamente difundidas em publicações e eventos recentes ${ }^{2}$, pretende-se abordar também alguns aspectos específicos no que se refere especificamente a produtos alimentares tradicionais protegidos por Indicações Geográficas (IGs).

Não propomos aqui uma contextualização das IGs em âmbito internacional e tampouco nos deteremos sobre os acordos e legislação pertinentes ao arcabouço teórico da Propriedade Intelectual. O objetivo central deste artigo é realizar uma discussão acerca da pertinência das Indicações Geográficas, tal como têm sido propostas no Brasil, como instrumento para valorização de produtos alimentares tradicionais.

Além da literatura referente ao tema, a análise tomará por base a Lista de IGs nacionais e estrangeiras registradas no Brasil, documento elaborado e divulgado pelo Instituto Nacional de Propriedade Intelectual (INPI), autarquia vinculada ao Ministério do Desenvolvimento Indústria e Comércio Exterior (Mdice).

\footnotetext{
I Segundo Flores (2006) esse conceito foi inicialmente tratado nas ciências naturais, estabelecendo a relação entre o domínio de espécies com uma determinada área física. Posteriormente, foi incorporado, pela geografia, relacionando espaço, recursos naturais, sociedade e poder. Mais recentemente, outras disciplinas passaram a incorporar esse conceito.

2 Neste parágrafo busca-se introduzir o tema, afirmando que em especial no Brasil é possível identificar que nos últimos dez anos cresceu o número de publicações e eventos acadêmicos e institucionais cujo tema central é as Indicações Geográficas.
} 


\section{Alimentos tradicionais: cultura alimentar e produtos tradicionais}

A expansão da indústria alimentar proporcionou mudanças substanciais, não apenas nos tipos de alimento que temos disponíveis, mas também em nossa relação com eles. As grandes superfícies e redes distribuidoras de alimentos, que constituem importante forma de abastecimento na contemporaneidade, ofertam toda espécie de produtos, em boa medida higienizados, processados e prontos para o consumo. É possível consumir quase todos os alimentos pelos quais se possa pagar, mas nem sempre é possível identificar de onde esses produtos vêm, como são produzidos e/ou quais riscos podem apresentar à saúde.

As cadeias agroalimentares, que desembocam nos grandes supermercados, estão estruturadas na impessoalidade na relação entre produtores e consumidores e no desconhecimento, pelos consumidores, sobre a origem e os processos envolvidos na produção de alimentos. Esse distanciamento entre produção e consumo, somado ao fato de ignorarmos a origem e formas de fabricação dos alimentos, parece causar questionamentos em parcela da população, estimulando nos consumidores uma atitude de desconfiança diante dos alimentos (Fischler, 1995; Menasche, 2003; Contreras, 2005; Acampora e Fonte, 2007). Nas palavras de Contreras (2005, p. 136), o "desconhecimento das formas de fabricação dos alimentos e das matérias-primas utilizadas gera confusão, uma vez que estimula nos consumidores uma atitude de desconfiança diante da oferta alimentar, muito mais abundante do que nunca”.

O que parece claro é que a industrialização do setor alimentar provocou severa ruptura de referências, mas os consumidores, peças-chave no processo complexo do qual participam sem controlar, continuam necessitando-as.

As crescentes inquietações a respeito da qualidade dos alimentos foram também impulsionadas por diversos escândalos alimentares, ocorridos especialmente nos anos 1980 e 90 -vaca louca, na Inglaterra; colza, na Espanha; dioxinas, na Bélgica; galinhas ${ }^{3}$, no Brasil, entre outros ${ }^{4}-\mathrm{e}$, mais recentemente, pela introdução no

\footnotetext{
3 Expressão utilizada originalmente pelo ambientalista brasileiro José Lutzenberger, para designar as modernas criações intensivas, alimentadas com milho, da empresa Pionneer, tratado com Aldrin, originalmente, apresentaram índices de contaminação de até quatro mil vezes o máximo permitido de resíduos tóxicos (Pinheiro, Nasr e Luz, 1993).

4 Recentemente houve no Brasil, o caso do Toddynho (ocorrido em setembro de 20II), em que, no Rio Grande do Sul, pelo menos 39 pessoas alegaram ter sofrido queimaduras após o consumo do achocolatado. Também o suco AdeS maçã apresentou alteração, decorrente de uma falha no processo de higienização, resultando no envase de embalagens com produto de limpeza.
} 
mercado de produtos elaborados a partir de grãos geneticamente modificados. Esse conjunto de fatores dá origem a um fenômeno conhecido como ansiedade contemporânea frente aos alimentos (Fischler, 1995; Menasche, 2003; Contreras, 2005; Acampora e Fonte, 2007; Dória, 2007).

A base para o entendimento desse fenômeno é fornecida por Fischler (1995). O autor constrói sua explicação a partir do fato do homem ser onívoro, ou seja, capaz de adaptar-se a diferentes dietas, podendo retirar de diversos alimentos os nutrientes necessários para sua sobrevivência. Por necessitar da variedade, o homem está motivado à inovação, à experimentação e à mudança. Contudo, essa situação o compele a ter prudência, desconfiança e certo conservadorismo, pois tudo o que é novo pode conter perigo potencial e apresenta risco. Desta forma, o homem oscila entre a neofilia - tendência ao novo, à experimentação- e a neofobia -tendência à desconfiança, à prudência e temor do desconhecido-, o que gera uma ansiedade fundada na relação do homem e a comida, daí o que o autor nomina como paradoxo do onívoro.

Esse temor encontra na sociedade contemporânea todas as condições para manifestar-se, justamente pela variedade de produtos e possibilidade de escolhas alimentares às quais estamos expostos. Do mesmo modo, riscos e temores parecem evidentes frente ao desconhecido, pois em muitos casos as tecnologias empregadas na produção de alimentos não deixam pistas do que se está realmente comendo. A expressão Objetos Comestíveis Não Identificados (OCNI) é utilizada por Fischler (I995) para abordar, com ironia, a situação de desconhecimento a respeito da comida à qual a sociedade contemporânea está sujeita.

O princípio da incorporação, também abordado por Fischler (1995), traz elementos que auxiliam na compreensão dos sentidos contidos na alimentação, visto que ao incorporar um alimento recebemos todas suas propriedades, sejam elas materiais ou simbólicas. Nesta perspectiva, os riscos estão presentes, pois o alimento desconhecido pode fazer mal -no sentido biológico- ou associar aquele que come a algo ou a alguma coisa da qual não se sente próximo.

Tibério, Cristóvão e Fragata (200I) apontam a crise da agricultura produtivista juntamente com a industrialização do setor alimentar como responsáveis pelas incertezas e desconfianças vividas por parte dos consumidores relativamente às condições de elaboração de produtos agroalimentares, situação que traz a questão da qualidade dos alimentos para o centro da discussão.

A constatação da perda de sabores, raças e receitas tradicionais locais levou, segundo Contreras (2005), a inúmeras operações de resgate de variedades e receitas, 
muitas com apoio financeiro do Estado. Aspectos como artesanal e tradicional passaram a ser valorizados mercadologicamente, levando ao crescente interesse dos produtores por selos distintivos, como as Indicações Geográficas, dentre outros (Contreras, 2005).

Nesse contexto, fortalecem-se movimentos, a exemplo daqueles relacionados ao Comércio Justo e do Movimento Slow Food's que evidenciam a existência de setores da população que percebem de maneira crítica o processo de padronização alimentar a que estamos submetidos.

Em síntese, pode-se afirmar que as reflexões proporcionadas pela literatura que trata da alimentação em uma perspectiva mais ampla e em um viés sócioantropológico ${ }^{6}$ levam a crer que as mudanças nas características organolépticas dos alimentos, as evidências da crise ambiental e o temor gerado pelo desconhecimento dos processos produtivos, aliados aos escândalos alimentares, são algumas das variáveis que conformam um novo cenário, em que emerge outro tipo de reflexão e comportamento em relação aos alimentos.

Dessa forma, se por um lado cresce a desconfiança a respeito da alimentação industrializada e o temor com relação à qualidade do que consumimos, por outro é identificada uma demanda por alimentos de procedência conhecida pelos consumidores e que remetem a valores associados ao bem estar animal e qualidade de vida (Krone, 2009; Krone e Menasche, 2010).

Assim, em contraponto à alimentação "sem memória", caracterizada pelo afastamento entre produção e consumo, Krone (2009) afirma que os produtos tradicionais aproximam e fortalecem aspectos como confiança, reputação, transparência e localidade, ademais de reunirem elementos que redefinem o próprio conceito de qualidade para os consumidores. Tibério e Cristóvão (200I), referindo-se ao contexto europeu em geral e a Portugal em particular, afirmam que a valoração atribuída a produtos tradicionais os torna elementos centrais para o desenvolvimento de áreas rurais menos favorecidas.

São várias as designações atribuídas a esses produtos, como alimentos tradicionais, produtos típicos, locais, territoriais, entre outros. Embora associadas

5 Associação internacional, fundada em 1989, como resposta aos efeitos do fast-food; ao ritmo frenético da vida atual; ao desaparecimento das tradições culinárias regionais; ao decrescente interesse das pessoas na sua alimentação, na procedência e sabor dos alimentos e em como nossa escolha alimentar pode afetar o mundo", www.slowfood.org.br.

6 Ver Mintz (200I), que apresenta uma breve revisão dos estudos antropológicos sobre alimentação.

7 Expressão utilizada por Contreras (2005). 
a diferenças de abordagens e ênfases, referem-se a produtos que possuem forte enraizamento em seu lugar de origem, capazes de mobilizar sentimentos de pertencimento, tradição, localidade e uma ancestralidade comum. Mediante a discussão realizada por Cruz (20I2), pode-se dizer que os produtos alimentares tradicionais ou alimentos tradicionais -denominações que serão utilizadas no decorrer deste trabalho-, são aqueles cujas práticas de produção e preparação, em contextos rurais, seguem modos de fazer rituais, conduzidos por produtores que detêm conhecimento e reputação necessários para perpetuar sua produção. Trata-se de modos de produção que envolve não apenas produto final, mas todo o processo, que vai desde a origem das matérias primas, modos de produzir, armazenar e consumir, nutrindo, no presente, os laços que ligam o passado ao futuro.

A valoração simbólica dos alimentos, sua relação com a cultura e com a identidade dos territórios têm, cada vez mais, encontrado eco em diferentes áreas do conhecimento, com destaque para a valorização dos alimentos na perspectiva do desenvolvimento territorial. A comida, o artesanato, a cultura e a importância social da agricultura familiar tornam-se elementos em destaque.

A produção acadêmica a respeito da agricultura familiar como categoria social estratégica para o desenvolvimento do rural brasileiro é vasta, tornando dispensável alongar-se no tema. Contudo é importante lembrar que no Brasil dos anos i990, conformou-se um cenário político que levou a agricultura familiar a ampliar sua visibilidade social e ao reconhecimento de sua importância na construção de um processo de desenvolvimento mais equitativo e sustentável. Nesse sentido, avança a perspectiva da valorização de sistemas tradicionais da agricultura familiar e diversas possibilidades vão sendo apontadas para o desenvolvimento dessa categoria e dos espaços rurais nos quais está inserida. Amplia-se a discussão sobre agroindustrialização familiar, turismo, serviços e, mais recentemente, utilização de produtos da sociobiodiversidade e valorização de produtos alimentares tradicionais característicos de territórios específicos.

Segundo Aguilar Criado, Anjos e Caldas (20II), elementos como paisagens, arquitetura, festas e gastronomia tornam-se -principalmente na Europa, mas também identificamos elementos desse processo em regiões brasileiras- pilares que sustentam o desenvolvimento rural, gerando uma nova marca: a de produto rural, cuja importância reside em suscitar elementos como tradição, história e natureza.

A elaboração e consumo de produtos alimentares tradicionais, como queijos, farinhas, doces e embutidos, são frutos de um saber que por vezes se mantêm por séculos, sendo que, em muitos casos, ocorre pouca ou nenhuma alteração no 
modo com que esses produtos são feitos. Desta forma, são alimentos dotados de sabores diferenciados, de significados e identidades únicas, para quem os produz e para quem os consome. Entretanto, ainda que seu valor seja reconhecido, os produtos tradicionais são frequentemente tratados como ilegais pelas instituições normatizadoras da produção de alimentos, estando sujeitos a constrangimentos em sua comercialização e circulação. Esses produtos estão inseridos em um ambiente institucional representado pelo arcabouço legal que rege a produção e comercialização de alimentos no Brasil. Todavia, esses aspectos não impedem que tais produtos sejam elaborados e apreciados por grande número de consumidores, isto é, por pessoas para quem as escolhas alimentares colocam-se acima dos aspectos legais associados aos produtos.

\section{Indicações geográficas: possibilidades para o contexto brasileiro}

Nos últimos dez anos, os produtos alimentares tradicionais são apontados como possibilidade de inclusão de determinados grupos no processo produtivo, valorizando suas práticas como elemento de obtenção de renda e criando possibilidades de desenvolvimento. Assim, a Propriedade Intelectual, por meio das Indicações Geográficas, tem sido acessada no Brasil, a exemplo do que ocorre há muito na Europa, como estratégia para valorização formal dos produtos tradicionais.

As Indicações Geográficas têm merecido muitos estudos, como os de Caldas (2004), Acampora e Fonte (2007), Benedetto (2007), Aguilar Criado et al. (20II), em que ganham destaque o território como espaço de produção de alimentos. A ele vem sendo associadas qualidades específicas de um produto, resultantes da junção de características socioculturais e fatores ambientais, conformando produtos singulares.

Tibério e Cristóvão (200I) lembram que, na conjuntura europeia, a valorização da origem geográfica dos produtos vem sendo desenvolvida no sentido de promover regiões rurais mais fragilizadas, pois diferenciação, qualidade e território são elementos a partir dos quais essas regiões podem se diferenciar. Para promover produtos com tais características a legislação brasileira prevê instrumentos associados ao regime de Propriedade Intelectual -referente à "proteção da criação humana, por meio da implantação do direito de apropriação ao homem sobre suas criações, obras e produções do intelecto, talento e engenho" (Wanghon e Costa, 2004, p. 167) -, em que se inserem as Indicações Geográficas. 
Os acordos internacionais que dão base às IGs têm como marco inicial a Convenção de Paris (1883), da qual o Brasil foi signatário. Posteriormente, destacam-se os acordos de Lisboa, de Madri e o que versou sobre aspectos dos Direitos de Propriedade Intelectual relacionados ao Comércio (Adpic ou Trips, na sigla em inglês) (Radomsky, 20ıо; Niederle, 20II).

No Brasil, a Propriedade Intelectual possui duas vertentes: os Direitos Autorais e a Propriedade Industrial. Os direitos autorais ou copyright referem-se a trabalhos literários, cinematográficos, fonográficos, artísticos em geral e, mais recentemente, a softwares (Wanghon e Costa, 2004). Por sua vez, a Propriedade Industrial se expressa segundo a Lei 9279/96 (Brasil, 20II), por meio de concessão de patentes de invenção e de modelo de utilidade, da concessão de registro de desenho industrial, da concessão de registro de marca, da repressão à concorrência desleal e da repressão às falsas Indicações Geográficas.

No contexto brasileiro, Indicação Geográfica é, portanto, uma modalidade de Propriedade Industrial e, segundo o Artigo 176 da Lei n.9279/96, pode apresentar-se de duas formas: Indicação de Procedência (IP) ou Denominação de Origem (DO). A Indicação de Procedência, segundo a referida Lei, “é caracterizada por ser o nome geográfico conhecido pela produção, extração ou fabricação de determinado produto, ou pela prestação de dado serviço, de forma a possibilitar a agregação de valor quando indicada a sua origem, independente de outras características”. A Denominação de Origem "cuida do nome geográfico que designe produto ou serviço cujas qualidades ou características se devam exclusiva ou essencialmente ao meio geográfico, incluídos fatores naturais e humanos”.

De acordo com o INPI, para receber a concessão de uma Indicação Geográfica para produtos alimentares, os requerentes devem contar com a mediação de uma entidade com característica de representação coletiva que congregue os produtores interessados em obter a concessão. A organização solicitará, então, por meio de formulário específico, o registro, agregando os demais documentos solicitados para cada caso ${ }^{8}$. Cabe ressaltar que, no caso de Indicação de Procedência, é necessária, além dos documentos descritos, a apresentação de elementos que comprovem que o nome geográfico se tornou conhecido como centro de elaboração do produto, enquanto que para a Denominação de Origem deverá ser apresentada descrição das características do produto devidas essencialmente ao meio geográfico, aí inclusos fatores naturais e humanos.

8 Para saber quais documentos são necessários acessar www.inpi.org.br 
Alguns estudos apresentados no decorrer do artigo têm discutido a importância das Indicações Geográficas como instrumento para certificar, atestar e fomentar o comércio de produtos específicos, como forma de garantir sua procedência e qualidade, diferenciando-os num universo de outros similares. A elas é atribuída a capacidade de contribuir para a manutenção da biodiversidade em geral e dos recursos genéticos, em particular, valorizando o enraizamento sociocultural dos produtos.

No Brasil, algumas publicações, sobretudo aquelas divulgadas por órgãos de fomento às Indicações Geográficas, apresentam uma perspectiva bastante otimista, situando seus esforços no sentido de divulgar, promover e incrementar o número de Indicações Geográficas no país (Kakuta, 2006; MAPA, 2009; Giesbrecht et al., 20I0).

Contudo, há também um considerável número de estudos recentes como Salavessa e Almeida (200I), Tibério e Cristóvão (200I), Tibério et al. (200I), Niederle e Vitrolles (2010), Niederle (20II), Froelich, (2012), Cerdan (2013), que abordam o tema das IGs em uma perspectiva mais crítica, buscando perceber as efetivas contribuições que o instrumento pode trazer em distintos campos: preservação de saberes, incremento mercadológico, preservação ambiental e certificação de qualidade, entre outras. Tais estudos tratam de sistemas produtivos em que estão queijos, vinhos, embutidos, entre outros. As reflexões propostas por essas pesquisas centram-se na verificação da pertinência deste instrumento para cada caso em estudo, levando em consideração o ambiente institucional e mecanismos de governança necessários.

Ao analisarmos a Lista de IGs concedidas ${ }^{9}$, identificamos que existem quarenta e cinco Indicações Geográficas concedidas pelo INPI, das quais oito são IGs estrangeiras, ou seja, produtos que possuíam reconhecimento em seus países de origem (França, Itália, Portugal e Estados Unidos) e que o solicitaram no Brasil. Os outros trinta e sete processos referem-se a produtos nacionais, sendo que vinte e três são produtos alimentares.

Os números elucidam a recente trajetória do país no assunto e, por outro lado, demonstram a intensificação dos processos de IGs. Os primeiros processos depositados no INPI datam de 1997, sendo que, em 1999, foi concedido o registro no Brasil da IG portuguesa do Vale dos Vinhos Verdes. A primeira IG brasileira, no entanto, foi solicitada em 2000 , vindo a ser concedida em $2002^{10}$. Após onze anos, o número de IGs para produtos alimentares subiu para vinte e três, sendo

9 Lista divulgada pelo INPI em Io de outubro de 2013. Ver: www.inpi.gov.br Io A Associação dos Produtores de Vinhos Finos do Vale dos Vinhedos (Aprovale), no Rio Grande do Sul, obteve a IP para vinhos tintos, brancos e espumantes. 
que dezoito delas foram obtidas entre 2010 e 2013. Ainda que, com o passar do tempo, os trâmites para a obtenção de IG estejam mais ágeis, permanecem sendo necessários em torno de dois anos.

Além do INPI, o Serviço Brasileiro de Apoio a Pequenas e Médias Empresas (Sebrae) e o Ministério da Agricultura Pecuária e Abastecimento (MAPA) atuam, com frequência, no tema das Indicações Geográficas. No MAPA, o suporte técnico aos processos de obtenção de registro de IG cabe à Coordenação de Incentivo à Indicação Geográfica de Produtos Agropecuários (CIG), do Departamento de Propriedade Intelectual e Tecnologia da Agropecuária (Depta), da Secretaria de Desenvolvimento Agropecuário e Cooperativismo (SDC). Ainda, esse Ministério divulga uma lista de "produtos potenciais", em que constam mais de roo produtos alimentares, espalhados por todos os estados brasileiros que, segundo a visão do MAPA, teriam potencial para tornar-se Indicação Geográfica, seja como Denominação de Origem ou Indicação de Procedência.

\section{Indicação geográfica para produtos alimentares tradicionais: novos mercados e certificação de qualidade}

A ampliação do número de Indicações Geográficas concedidas no país, o maior interesse da academia e o foco de instituições públicas no tema deixam claro que a valorização de produtos tradicionais via IGs tem conquistado espaço em diferentes esferas de discussão e de ação governamental. Nessa perspectiva, há aspectos que se destacam como justificativas para o investimento em longos e dispendiosos processos de obtenção de IGs para produtos alimentares tradicionais, entre eles a possibilidade de acesso a novos mercados e a obtenção de certificação da qualidade.

No que se refere ao acesso a novos mercados, há que considerar que, no caso de produtos alimentares tradicionais, essa possibilidade deve ser relativizada por duas questões centrais. A primeira delas, os produtos alimentares apenas poderão acessar novos mercados caso seus sistemas de produção estejam de acordo com a legislação que rege a produção, circulação e comercialização de produtos alimentares no Brasil. Para isso, faz-se necessária ampla conversão dos sistemas tradicionais (práticas, utensílios, instalações) a sistemas modernizados, o que, frequentemente, leva ao desaparecimento das práticas tradicionais, o que resulta em um contrassenso, pois as IG se propõem a proteger tais sistemas tradicionais. 
Froelich (20I2) salienta que, no Brasil, para além de reconhecer uma tradição consagrada, frequentemente as estratégias de IGs têm que conviver com uma tensão entre tradição e inovação. Para o autor, se por um lado o consumidor associa os produtos a ingredientes e práticas tradicionais, o progresso tecnológico promove crescente alteração nas condições de elaboração dos produtos. Assim, cabe a indagação apresentada pelo autor: "Quais seriam os limites das inovações para que não se descaracterize o que é considerado tradição?” (Froelich, 20I2, p. 502).

Muitas vezes, as instalações onde os produtos são processados estão de acordo com práticas transmitidas através de gerações, fazendo parte de um sistema complexo, fruto da experimentação e do trabalho das comunidades envolvidas. O lugar e os modos de produzir e trabalhar faz sentido para os produtores, contudo não são reconhecidos pelas instituições reguladoras, pois, em geral, vão de encontro a normas vigentes. Nesses casos, a possibilidade de acessar novos mercados torna-se remota, visto que, embora sejam tradicionais, consumidos e produzidos há muito tempo, tais produtos encontram-se na ilegalidade.

A segunda questão é que, para abarcar novos mercados, é necessário que haja produção suficiente para atender a novos circuitos. $O$ fato é que os sistemas tradicionais de produção de alimentos são, em boa medida, resultantes de trabalho familiar, baseados em pequena escala de produção, em que o volume produzido está intimamente associado à força de trabalho disponível na unidade familiar e a seu modo de vida. Assim, cabe indagar se os sistemas tradicionais têm possibilidade de abarcar novos mercados ou se, antes, não lhes faltam condições para melhor colocarem-se nos próprios circuitos tradicionais.

Cabe ressaltar que grande parte dos sistemas tradicionais de produção permaneceu e se desenvolveu à margem de processos formais, percurso resultante da resistência de produtores, que, ao deixarem de adotar sistemas modernizados, mantêm práticas tradicionais, tornando-se o que Giddens (1997) denominou guardiões das tradições.

Além dos impedimentos legais impostos pela legislação brasileira sobre alimentos, existem outras questões de estrutura que, em alguma medida, atingem a produção tradicional, a exemplo da má qualidade das estradas, falta de assistência técnica e acesso a bens e serviços. É nesse contexto, refletindo sobre os casos europeu e português, que Cristóvão (2002) propõe sejam pensadas outras medidas valorizadoras além das Indicações Geográficas, medidas que poderiam ser estruturantes para que os processos de IG não se tornem um fim em si. 
No que se refere à certificação de qualidade via Indicações Geográficas, alguns aspectos precisam ser avaliados, inclusive o próprio conceito de qualidade. Nos circuitos de alimentos tradicionais, em oposição ao que hoje ocorre nas formas globais de abastecimento, existe uma intima relação entre produtores e consumidores. Muitas vezes, são pessoas que se conhecem e que compartilham sistemas classificatórios referentes à qualidade dos produtos.

Cassarino e Ferreira (2013), referindo-se aos produtos agroecológicos -que, assim como os tradicionais, costumam ser marcados por estreita relação entre produtores e consumidores-, identificam uma "rastreabilidade" socialmente construída e, "mais que a técnica ou o controle físico da origem do produto, o diálogo e a transparência no processo de produção e consumo viabilizam esta rastreabilidade" (Cassarino e Ferreira, 2013, p. 190).

Tibério e Cristóvão (2007), em estudo sobre a realidade de Trás dos Montes, em Portugal, mostram que, nos casos de animais vivos -como bovinos, ovinos e caprinos- e de alguns tipos de produtos processados, como queijos, dada a pequena escala dos produtores, as trocas de informações ocorrem por meio do contato direto entre produtor e consumidor, sendo desnecessário o recurso a qualquer tipo de identificação ou qualificação. Segundo os autores, as transações estão baseadas na "confiança e no conhecimento mútuo e o consumidor valoriza, sobretudo, aspectos da dimensão organoléptica e simbólica” (Tibério e Cristóvão, 2007, p. II).

Em pesquisa recente sobre o Queijo Serrano dos Campos de Cima da Serra, no Rio Grande do Sul, Cruz (20I2) destaca que, naquele contexto, a qualidade do queijo é atributo compartilhado por produtores e consumidores, que se referem às mesmas categorias quando falam de qualidade (capricho, higiene), que é assegurada pelo interconhecimento existente entre eles. Naquela realidade, não existe um mediador externo que assegure ao consumidor a qualidade do produto, são as relações de confiança que o fazem.

\section{Indicação geográfica para produtos alimentares tradicionais: institucionalidade e diversidade}

Um dos requisitos para o processo de construção de uma IG é a necessidade de um grupo formalizado, seja uma associação ou cooperativa. Todavia, existem regiões em que os processos de organização social ocorrem por outras vias, como parcerias 
entre vizinhos e ações solidárias, que não necessariamente se traduzem em estrutura associativa formalizada. Nessas situações, para que o processo de valorização de produto tradicional ocorra via IG faz-se necessário forjar algum tipo de associação.

Cabe, nesse quadro, refletir se a criação de uma estrutura exclusivamente com esse objetivo seria capaz de sintetizar os processos organizativos de um território e em que medida os processos já existentes poderiam ser aprimorados para serem utilizados como vetores da criação de IGs. Contudo, ainda que não seja prática habitual em determinado território, a criação de um grupo formalmente organizado pode constituir-se em oportunidade para que os atores experimentem outras formas organizativas, que podem vir a ser benéficas, facilitando o acesso a outras políticas públicas que priorizam esse tipo de organização.

A partir de pesquisa realizada na região do Vale dos Vinhedos, no Rio Grande do Sul, Niederle (20II) evidencia que os processos de Indicação Geográfica no Brasil se encontram em terreno movediço. A metáfora é utilizada pelo autor para indicar que existem muitas imprecisões, pois as definições a respeito do papel das instituições envolvidas nos processos não são claras, visto que os atores carecem de normas consolidadas sobre a titularidade do certificado, as exigências para compor o dossiê e as formas de controle pertinentes.

O processo de obtenção de uma IG prevê, segundo o INPI, a existência de uma estrutura de controle sobre os produtores ou prestadores que tenham o direito ao uso exclusivo da Indicação Geográfica e seu produto ou serviço. Esse controle é responsável por determinar quais produtores estão conforme os critérios adotados para a implantação da IG, sendo que aqueles que não cumprem as regras ficam fora do processo. Um modelo dessa natureza pode levar a selecionar grupos mais aptos técnica e economicamente, em detrimento de outros que não se enquadram nas normatizações.

No caso dos produtos alimentares tradicionais, faz-se necessária cautela a esse respeito, pois em sua grande maioria se constituíram na diversidade: os produtos possuem características similares, todavia não são idênticos. Trata-se de um sistema em que há expressão de diferentes modos de fazer, características particulares impressas "pelas mãos” de quem faz. Assim, um processo de padronização pode acarretar na perda de características importante de um produto, as mesmas características que lhe conferiram notoriedade em dado território.

Recentemente, o MAPA elegeu seis ${ }^{\mathrm{II}}$ produtos potenciais para serem convertidos em IG, os quais deverão receber, por determinado período, apoio institucional para

II Informação obtida durante pesquisa de campo realizada em agosto de 2013, na região dos Campos de 
estímulo do processo. Um exemplo desse tipo de intervenção institucional pode ser visto no sistema do Queijo Serrano, indicado pelo MAPA como um dos produtos prioritários. Naquele contexto, estudo realizado por Vitrolles (20II) mostra que um processo de IG pode acarretar na perda de receitas e saberes característicos, visto que, para a obtenção da IG, outros procedimentos terão, necessariamente, que ser adotados.

Em pesquisa realizada junto a organizações espanholas representativas da agricultura familiar, Froelich (2012) aponta que, embora haja perspectivas diferentes entre as instituições, todas concordam que apenas a IG não é capaz de promover o desenvolvimento dos territórios, salientando a necessidade de situar as estratégias de IG a partir de uma visão global do território e das relações nele estabelecidas.

Em estudos realizados no contexto português, Tibério e Cristóvão (200I) abordam o caso da Denominação de Origem Protegida (DOP) Queijo Terrincho, avaliando os resultados obtidos nos seguintes itens: investimento, criação de empregos, retenção de valor na área geográfica de produção e melhoria do rendimento dos produtores. A análise dos dados conduz à conclusão de que, da forma com que está sendo operacionalizada, a DOP não cumpre com seus propósitos.

Os problemas identificados no estudo português mostram que, mesmo na Europa, onde os processos de Indicações Geográficas têm uma longa trajetória, é preciso repensar os modelos implementados. Assim, no Brasil, onde apenas se inicia uma caminhada, estudos podem aportar elementos para que os processos construídos sejam reorientados e particularizados, buscando construir propostas que atendam às singularidades dos sistemas produtivos, sobretudo os alimentares. Cerdan (2013) alerta para a falta de estudos que avaliem os potenciais perigos implicados na implantação de uma IG, sobretudo aqueles relacionados à sobre-exploração de recursos naturais que, em função de uma IG, encontram-se valorizados no mercado. Como exemplo deste risco, pode-se pensar no sistema brasileiro do capim dourado (Syngonantus nitens), que na região do Jalapão, estado do Tocantins, mediante crescente valorização como matéria prima de produtos artesanais, tem se tornado vulnerável à pressão exploratória (Alves, 2008).

Em pesquisa de campo realizada em Minas Gerais, em abril e maio de 2013, constatou-se que entre os produtores de dois queijos artesanais mineiros -Queijo do Serro e Queijo da Canastra- naquele momento nenhum tinha aderido à utilização do selo da IG, embora contassem com a concessão do registro desde 20 II e 20 I2.

Cima da Serra, Rio Grande do Sul, Brasil. 
Processo equivalente ocorre com o Arroz do Litoral Norte Gaúcho, primeira Denominação de Origem para produtos brasileiros. Embora seja possuidor da concessão do INPI desde 20ro, a pesquisa de Haas e Froelich (2013) não identificou no mercado produto sendo comercializado com o selo da IG.

Calliari (2007) advertem que processos de Indicação Geográfica devem levar em conta, além de fatores que tipificam o local, o perfil dos produtos e o vínculo entre esses produtos e as condições regionais. Para os autores, conjuntamente com o processo de promoção de IG, é preciso um trabalho de valorização desses produtos junto a consumidores, pois identificam que, no contexto brasileiro, a Indicação Geográfica é valorizada, em produtos importados, por consumidores de maior renda. Contudo, no caso de produtos brasileiros, é desconhecida tanto por produtores e comerciantes quanto pela maior parte dos consumidores.

Assim, torna-se evidente que, anterior à escolha da valorização de determinados produtos via de Indicações Geográficas, os territórios devem ser avaliados de forma mais ampla, para então definir qual a melhor estratégia para valorização de seus sistemas alimentares. O primeiro passo é que os atores envolvidos no processo tenham conhecimento de cada sistema de produção alimentar tradicional em questão e possam interpretá-lo buscando proteger suas características essenciais.

Os produtores locais, que são, em última instância, os guardiões de saberes e práticas tradicionais, precisam ser ouvidos e respeitados, sendo importante que lhes seja informado o que podem esperar como resultado do processo de instituição de Indicação Geográfica referente a seu produto.

\section{Conclusões}

Ainda que frequentemente apontada como um processo viável, parece claro que ainda se tem muito que avançar no entendimento das possibilidades de aplicação das IGs para produtos alimentares no Brasil. Cerdan (2013) identifica dificuldades metodológicas para avaliar os efeitos de uma IG em um território e alerta que as avaliações dependem das visões de quem as realiza, podendo mensurar apenas o que esse considera importante. Assim, para além da necessidade de avaliações, cabe observar quem as realiza e quais os interesses envolvidos. A autora lembra, ainda, que em muitos casos os trabalhos de análise dos impactos das IGs estão centrados no produto e na cadeia produtiva, furtando-se de contextualizar a IG nos territórios e de identificar dinâmicas existentes que podem ou não ser sinérgicas. 
As instituições envolvidas em processos de Indicações Geográficas, seja da esfera pública ou organizações de produtores, precisam verificar se o investimento em IG é apropriado para a realidade em que seus produtos estão inseridos. Os produtores têm efetivamente intenção, necessidade e condições de ampliar sua produção e acessar novos mercados? Os questionamentos acerca da qualidade dos produtos serão respondidos se este sistema se constituir em uma Indicação Geográfica?

Além das IGs, alguns países estão criando mecanismos próprios de valorização e produção de conhecimento sobre produtos tradicionais. Como exemplo podemos citar, no Brasil, o Registro de Bens Culturais de Natureza Imaterial (Rbcni) e conforme Oliveira (2004), a constituição de bancos de dados na Venezuela.

Conforme discutido ao longo do artigo, muitas vezes produtos alimentares tradicionais possuem carências anteriores e de outras ordens, que devem ser sanadas antes que seja buscado um processo de valorização formal via Indicações Geográficas.

\section{Referências}

Acampora, T. e Fonte, M. (2007). Productos típicos, estrategias de desarrollo rural y conocimiento local. Revista Ópera, (07), I9I-212.

Aguilar Criado, E., Anjos, F. e Caldas, N. (20II). Productos locales, calidad y diversificación: nuevas estrategias de desarrollo en el mundo rural de España y Brasil. Estudos Sociológicos, 29(85), I89-2I4.

Alves, H. (2008). A percepção das comunidades extrativistas e artesanais do CE (Corredor Ecológico) Jalapão sobre a sustentabilidade da exploração do capim dourado (Syngonantus nitens). Dissertação para obter o título de mestre em Planejamento e Gestão Ambiental, Universidade Católica de Brasília, Brasília. Benedetto, A. (2007) Valorización de la identidad territorial, políticas públicas y estrategias de desarrollo territorial en los países del Mercosur. Revista Ópera, (7), 139-165.

Brasil (20II). Lei 9.279 de I4 de maio de 1996. Regula direitos e obrigações relativos à propriedade industrial. Recuperado el 27 de julho de 201 , de http://www. planalto.gov.br/ccivil_03/Leis/L9279.htm

Caldas, A. (2004) Novos usos do território: as indicações geográficas protegidas como unidades de desenvolvimento regional. Análise E• Dados, (I4), 593-602. 
Calliari, M. (2007). Proteção às indicações geográficas: a experiência brasileira. Em XII Seminário Latino-Iberoamericano de Gestion Tecnológica-Altec. Buenos Aires: Autor. Recuperado el 6 de março de 20ıo, de http://www.asociacionaltec. org/Documents/40292.pdf

Cassarino, J. e Ferreira, A. (20I3). Agroecologia, construção social de mercados e a constituição de sistemas agroalimentares alternativos: uma leitura a partir $\mathrm{da}$ rede ecovida de agroecologia. Em P. Niederle, L. Almeida e F. Vezzani (Orgs.), Agroecologia: práticas, mercados e políticas para uma nova agricultura (pp. I7I-2I4). Curitiba: Kairós.

Cerdan, C. (2013). Indicações geográficas e estratégias de desenvolvimento territorial. Em P. Niederle (Orgs.), Indicações geográficas: qualidade e origem nos mercados alimentares (pp. I25-150). Porto Alegre: Ufrgs.

Contreras, H. (2005) Patrimônio e globalização: o caso das culturas alimentares. Em A. Canesqui e R. Garcia (Orgs.), Antropologia e nutrição: um diálogo possível (pp. I45-I59). Rio de Janeiro: Fiocruz.

Cristóvão, A. (2002) Mundo rural: entre as representações (dos urbanos) e os benefícios reais (para os rurais). Em M. Riedl, J. Almeida e A. Viana (Orgs.), Turismo rural: tendências e sustentabilidade (pp. 8I-II6). Santa Cruz do Sul: Edunisc.

Cruz, F. (20I2). Produtores, consumidores e valorização de produtos tradicionais: um estudo sobre qualidade de alimentos a partir do caso do Queijo Serrano dos Campos de Cima da Serra. Tese doutorado em Desenvolvimento Rural, não publicada. Universidade Federal do Rio Grande do Sul, Porto Alegre.

Dória, C. (2007). A economia política do terroir: o estado e a magia do produto. Em Seminário Pensando o consumo boje: novas abordagens (pp. I-I4). São Paulo: ESPM/ Caepm.

Fischler, C. (1995). El (b)omnivoro: el gusto, la cocina y el cuerpo. Barcelona: Anagrama. Flores, M. (2006). A identidade cultural do território como base de estratégias de desenvolvimento, uma visão do estado da arte. InterCambios, I(64). Recuperado el I6 de abril de 20II, de http://www.rimisp.org/getdoc.php?docid=3736

Froelich, J. (20I2). Indicações geográficas e desenvolvimento territorial, as percepções das organizações representativas da agricultura familiar na Espanha. Estudos Sociedade e Agricultura, 2(20), 485-508.

Giddens, A. (1997). A vida em uma sociedade pós-tradicional. Em U. Beck, A. Giddens e S. Lash (Orgs), Modernização reflexiva: política, tradição e estética na ordem social moderna (pp. 207-255). São Paulo: Unesp. 
Giesbrecht, H., Schwanke, F. e Müssnich, A. (2010). Catálogo das indicações geográficas brasileiras. Brasília: Sebrae.

Haas, J. e Froelich, J. (20I3). Estratégias de qualidade de base territorial e commodities - o caso do arroz irrigado na Andaluzia e no Rio Grande do Sul.

Memorias del VI Congresso Internacional de Sistemas Alimentares Localizados (pp. 2-27). Florianópolis: Universidade Federal de Santa Catarina.

Instituto Nacional de Propriedade Intelectual [INPI] (2000). Resolução № 75.

Recuperado el 20 de maio de 20I2, de http://www.inpi.org.br/legislacoes

INPI (2013). Lista de IGs nacionais e estrangeiras registradas no Brasil. Recuperado el o7 de outubro de 2013, de http://http://www.inpi.gov.br/images/docs/indicacoes_ geograficas_concedidas_or_Io_20I3.pdf

Kakuta, S. (2006). Indicações geográficas: guia de respostas. Porto Alegre: Sebrae/RS.

Krone, E. (2009). Identidade e cultura nos Campos de Cima da Serra (RS):

práticas, saberes e modos de vida de pecuaristas familiares produtores do Queijo Serrano. Dissertação para obter o título de mestre em Desenvolvimento Rural, Universidade Federal do Rio Grande do Sul, Porto Alegre.

Krone, E. e Menasche, R. (2010). Políticas públicas para produtos com identidade cultural: uma reflexão a partir do caso do Queijo Artesanal Serrano do sul do Brasil. Memórias del VIII Congresso Latino-Americano de Sociologia Rural, Porto de Galinhas: Alasru.

Menasche, R. (2003). Os grãos da discórdia e o risco à mesa: um estudo antropológico das representações sociais sobre cultivos e alimentos transgênicos no Rio Grande do Sul. Tese de doutorado em Antropologia Social, não publicada, Universidade Federal do Rio Grande do Sul, Porto Alegre.

Ministério da Agricultura, Pecuária e Abastecimento (2009). Curso de propriedade intelectual E inovação no agronegócio, módulo II: indicação geográfica. Brasília: $\mathrm{SEAD/UFSC/Fapeu.}$

Mintz, S. (200I). Comida e antropologia: uma breve revisão. Revista Brasileira de Ciências Sociais, I6(47), 3I-38.

Niederle, P. (20II). Compromissos para a qualidade: projetos de indicação geográfica para vinhos no Brasil e na França. Tese de doutorado em Ciências Sociais, não publicada, Universidade Federal Rural do Rio de Janeiro.

Niederle, P. e Vitrolles, D. (2010). Indicações geográficas e qualificação no setor vitivinícola brasileiro. Estudos Sociedade e Agricultura, I8(I), 5-55.

Oliveira, A. (2004). Salvaguarda do patrimônio cultural: bases para a constituição de direitos. Conferencia apresentada em el Seminário Propriedade Intelectual 
e Patrimônio Cultural: proteção do conhecimento e das expressões culturais tradicionais. Belém: Cesupa/MPEG.

Pinheiro, S., Nasr, N. e Luz, D. (1993). A agricultura ecológica e a máfia dos agrotóxicos no Brasil. Porto Alegre: Edição dos Autores.

Radomsky, G. (2010). Propriedade intelectual e certificação de produtos da agricultura ecológica. Em O. Fachel e R. Hennemann (Orgs.), Do regime de propriedade intelectual: estudos antropológicos (pp. 199-223). Porto Alegre: Tomo.

Salavessa, J. e Almeida, C. (200I). Perspectiva de certificação do Queijo Cabra, um fator de desenvolvimento da Região do Pinhal do Sul. Conferencia apresentada ao I Congresso de Estudos Rurais: Território, Agricultura e Desenvolvimento. Vila Real: UTAD e Sociedade Portuguesa de Estudos Rurais.

Slow Food Brasil (2012). Recuperado el 24 de junho de 20I2, de http://www. slowfoodbrasil.com

Tibério, M. e Cristóvão, A. (200I). Produtos tradicionais e desenvolvimento local: o caso da designação protegida Queijo Terrincho DOP. Conferencia presentada ao I Congresso de Estudos Rurais. Território, Agricultura e Desenvolvimento. Vila Real: UTAD e Sociedade Portuguesa de Estudos Rurais.

Tibério, L. e Cristóvão, A. (2007). Tipicidade, especificidade e qualidade dos produtos agro-alimentares tradicionais: o caso dos produtos DOP/IGP de Trásos-Montes. Em T. Dentinho e O. Rodrigues (Coords.), Periferias e Espaços Rurais. Comunicações apresentadas ao II Congresso de Estudos Rurais. Estoril: Princípia.

Tibério, M., Cristóvão, A. e Fragata, A. (200I). Produtos tradicionais e construção da qualidade: o caso das designações protegidas Salpicão de Vinhais (IGP) e Linguiça de Vinhais (IGP). IV Coloquio Hispano-Portugués de Estudios Rurales: la multifuncionalidad de los espacios rurales de la península Ibérica. Santiago de Compostela: Associação Espanhola de Economia Agrária e Sociedade Portuguesa de Estudos Rurais.

Vitrolles, D. (20II). When Geographical Indication Conflicts with Food Heritage Protection. The Case of Serrano Cheese from Rio Grande do Sul, Brazil. Anthropology of Food, (8). Recuperado el 30 de maio de 20I3, de http://aof.revues. org/index6809.html

Wanghon, M. e Costa, C. (2004). Indicações geográficas como instrumento de proteção do patrimônio cultural imaterial. Seminário Propriedade Intelectual e Patrimônio Cultural: Proteção do Conbecimento e das Expressões Culturais Tradicionais. Belém: Cesupa/MPEG. 